\title{
Morphometric analysis of Triatoma dimidiata populations (Reduviidae:Triatominae) from Mexico and Northern Guatemala
}

\author{
P Lehmann, R O rdoñez, R O jeda-Baranda*, J Mendez de Lira**, L Hidalgo-Sosa***, \\ C Monroy****, JM Ramsey $/^{+}$
}

Centro de Investigaciones sobre Enfermedades Infecciosas, Instituto Nacional de Salud Pública, Av. Universidad 655, Cuernavaca, Morelos, México 62508 *Secretaria de Salud del Estado de Yucatan, Merida, México **Secretaria de Salud del Estado de San Luis Potosi, Cd. Valles, Mdéxico ***Secretaria de Salud del Estado de Veracruz, Jalapa, México ****Universidad San Carlos, Laboratorio de Entomologia Aplicada y Parasitologia, Guatemala

Triatoma dimidiata is one of the major vectors of Chagas disease in Latin America. Its range includes Mexico, all countries of Central America, Colombia, and Ecuador. In light of recent genetic analysis suggesting that the possible origin of this species is the Yucatan peninsula, we have analyzed populations from the state of Yucatan, San Luis Potosi, and Veracruz in Mexico, and a population from the southern region of the Yucatan peninsula located in Northern Guatemala, the region of El Peten. Classical morphometry including principal component, discriminant, sexual dimorphism, and wing asymmetry was analyzed. San Luis Potosi and Veracruz populations were indistinguishable while clearly separate from Yucatan and Peten populations. Despite important genetic differences, Yucatan and Peten populations were highly similar. Yucatan specimens were the smallest in size, while females were larger than males in all populations. Only head characters were necessary to distinguish population level differences, although wing fluctuating asymmetry was present in all populations. These results are discussed in light of recent findings suggesting genetic polymorphism in most populations of Triatoma dimidiata south of Chiapas to Ecuador.

Key words: Triatoma dimidiata - Chagas disease - morphometry - Mexico - Guatemala

Triatoma dimidiata is a triatomine species (Reduviidae:Triatominae) which naturally spans both North and South America, and represents one of the major vectors of Chagas disease in all countries where it is present. Its range includes Mexico, all countries of Central America, Colombia, and Ecuador. The species was tentatively assigned to the phyllosoma complex by Lent and Wygodzinsky in 1979, pending further studies on nymph stages. In Mexico, T. dimidiata has been identified in domestic habitats within 13 states (Zarate \& Zarate 1985, Vidal-Acosta et al. 2000). These states are located in four principal geographic regions: the Yucatan peninsula (Yucatan, Campeche, Quintana Roo), the Gulf coast of Mexico (Tabasco, Veracruz, San Luis Potosi, Hidalgo), the high plains (Oaxaca, Morelos, Mexico), and the Pacific coast (Jalisco, Guerrero, Chiapas). Sampling has been limited, usually involving small-scale entomological or epidemiological studies. In some regions, collections may represent isolated dispersion assisted by human population migration, rather than real infestation.

T. dimidiata from the Yucatan peninsula is genetically distinct from other specimens collected from continental Mexico, by the substitution of 14 nucleotides in the ITS2 rDNA sequence (Marcilla et al. 2001), and by an $11 \%$ sequence divergence using LSU, ND4, and cyt b markers (Harris, pers. commun.). The principal and presumed origi-

${ }^{+}$Corresponding author. E-mail: jramsey@insp.mx. Received 28 October 2004

Accepted 4 July 2005 nal T. dimidiata genotype is distributed throughout the Yucatan peninsula, where the species is usually collected below $100 \mathrm{~m}$ above sea level (masl), and where the species is primarily sylvan or peridomestic. A second genotype is distributed from San Luis Potosi to Chiapas with only minor foci between eastern and western Sierra Madre, or the Pacific coast. The most complete inventories of this species in domestic habitats originate from the states of Veracruz (259 communities), San Luis Potosi (63 communities), and Hidalgo (34 communities), representing more than $78 \%$ of the total collection of the species in Mexico. Greater than $90 \%$ of the collections from this region are located below 700 masl, where the populations are highly domestic (Ramsey et al. 2003).

In order to characterize further the genetically and epidemiologically distinct populations of $T$. dimidiata, the present study used traditional morphometry to analyze populations collected from the northern region of the Yucatan peninsula (genotype 1, Marcilla et al. 2001), San Luis Potosi which is the northern limit of the species in Mexico (genotype 2, Marcilla et al. 2001), Veracruz which is similar to the former from the Gulf coast region and highly domestic (genotype 2, Marcilla et al. 2001), and one population collected south of the Yucatan peninsula in the sylvan region of Peten, Guatemala (genotype 3, Marcilla et al. 2001).

\section{MATERIALS AND METHODS}

Insects - A total of $187 \mathrm{~T}$. dimidiata adult specimens belonging to four population groups were studied (Fig. 1, Table). Populations were selected based on environmental or genetic information, and all samples were collected from either domestic (defined as the space contained 
within the main walls of the dwelling where household members sleep), peridomestic (area outside the main walls of the dwelling which belong to and is used by household members for family activities), or sylvan sites. The first population was collected from peridomestic sites in the state of Yucatan (57 individuals: 22 females and 35 males), samples from Veracruz were collected in domestic sites and included 33 individuals (18 females and 15 males), and specimens from San Luis Potosi were collected in domestic sites and included 50 individuals (20 females and 30 males). Specimens from Guatemala were collected from El Peten region, which is contiguous with the Yucatan Peninsula. These samples included 47 individuals $(25 \mathrm{fe}-$ males and 22 males), all from tropical rain forest sylvan sites within the Yaxha archaeological site, located in Melchor de Mencos, Peten, Guatemala. Wings and heads were dissected from each specimen following previous measurement of the complete length of each individual (except for Peten where wings and heads were separated from the bugs before complete size could be measured). The heads were preserved in $70 \%$ ethanol, and the wings were mounted on slides using Hoyer's medium.

Morphometric measurements of head and wings Head and wing morphometric distances were measured using a stereoscopic microscope, fitted with an ocular micrometer and a 2-fold magnification for heads, and with-

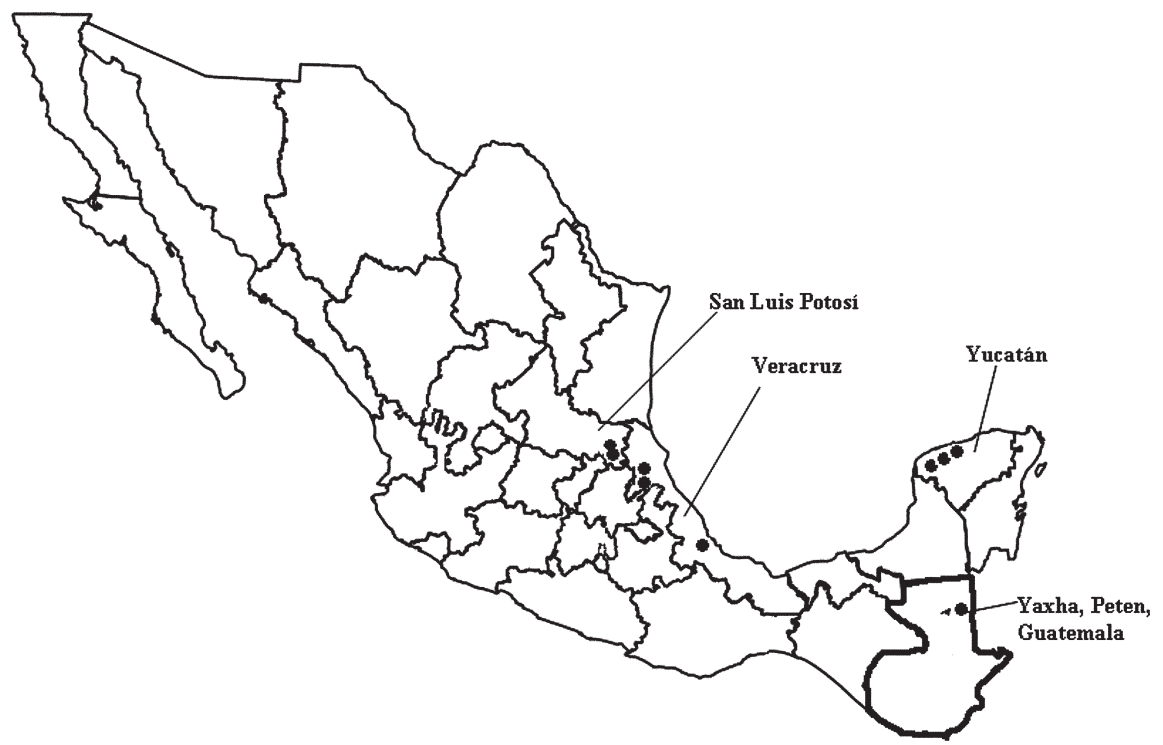

Fig. 1: map of Mexico and Guatemala, showing collection sites for Triatoma dimidiata in the Yucatán, Veracruz, and San Luis Potosí in Mexico, and Yaxha, Peten in Guatemala (see Table).

TABLE

Collection sites for Triatoma dimidiata used in morphometric analyses

\begin{tabular}{|c|c|c|c|c|c|}
\hline Community & County & State & $\begin{array}{c}\text { Longitude } \\
(\mathrm{deg} / \mathrm{min} / \mathrm{s})\end{array}$ & $\begin{array}{c}\text { Latitude } \\
(\mathrm{deg} / \mathrm{min} / \mathrm{s})\end{array}$ & $\begin{array}{c}\text { Altitude } \\
\text { (masl) }\end{array}$ \\
\hline Xolol & San Antonio & San Luis Potosi & $98^{\circ} 52^{\prime} 50^{\prime \prime}$ & $21^{\circ} 38^{\prime} 00^{\prime \prime}$ & 220 \\
\hline Lejem & San Antonio & San Luis Potosi & $98^{\circ} 51^{\prime} 52^{\prime \prime}$ & $21^{\circ} 36^{\prime} 39^{\prime \prime}$ & 240 \\
\hline Tanchahuil & San Antonio & San Luis Potosi & $98^{\circ} 54^{\prime} 02^{\prime \prime}$ & $21^{\circ} 35^{\prime} 37^{\prime \prime}$ & 300 \\
\hline Huayal & San Antonio & San Luis Potosi & $98^{\circ} 50^{\prime} 56^{\prime \prime}$ & $21^{\circ} 36^{\prime} 42^{\prime \prime}$ & 390 \\
\hline Ojos & Tanlajas & San Luis Potosi & $98^{\circ} 52^{\prime} 38^{\prime \prime}$ & $21^{\circ} 39^{\prime} 14^{\prime \prime}$ & 180 \\
\hline Coromohon & Tanlajas & San Luis Potosi & $98^{\circ} 53^{\prime} 30^{\prime \prime}$ & $21^{\circ} 40^{\prime} 50^{\prime \prime}$ & 140 \\
\hline Quelabitad & Tanlajas & San Luis Potosi & $98^{\circ} 57^{\prime} 42^{\prime \prime}$ & $21^{\circ} 42^{\prime} 32^{\prime \prime}$ & 70 \\
\hline Tamaletom & Tancanhuitz de Santos & San Luis Potosi & $98^{\circ} 56^{\prime} 07^{\prime \prime}$ & $21^{\circ} 36^{\prime} 10^{\prime \prime}$ & 200 \\
\hline Cerro & San Martin Chalchicuautla & San Luis Potosi & $98^{\circ} 40^{\prime} 57^{\prime \prime}$ & $21^{\circ} 27^{\prime} 55^{\prime \prime}$ & 120 \\
\hline Chicuasen & Actopan & Veracruz & $96^{\circ} 40^{\prime} 20^{\prime \prime}$ & $19^{\circ} 31^{\prime} 40^{\prime \prime}$ & 360 \\
\hline Marcialto & Ixhuatlan de Madero & Veracruz & $97^{\circ} 59^{\prime} 24^{\prime \prime}$ & $20^{\circ} 48^{\prime} 23^{\prime \prime}$ & 140 \\
\hline Corral Falso & Tepetzintla & Veracruz & $97^{\circ} 52^{\prime} 25^{\prime \prime}$ & $21^{\circ} 05^{\prime} 08^{\prime \prime}$ & 120 \\
\hline Cuahualeloco & Ixhuatlan de Madero & Veracruz & $98^{\circ} 00^{\prime} 28^{\prime \prime}$ & $20^{\circ} 48^{\prime} 21^{\prime \prime}$ & 180 \\
\hline Pedro Gde. Chijolito & Ixhuatlan de Madero & Veracruz & $97^{\circ} 59^{\prime} 24^{\prime \prime}$ & $20^{\circ} 48^{\prime} 01^{\prime \prime}$ & 140 \\
\hline Rancho San Antonio & Yaxkukul & Yucatan & $89^{\circ} 25^{\prime} 12^{\prime \prime}$ & $21^{\circ} 03^{\prime} 42^{\prime \prime}$ & 8 \\
\hline Dzibichaltun & Merida & Yucatan & $89^{\circ} 35^{\prime} 57^{\prime \prime}$ & $21^{\circ} 05^{\prime} 50^{\prime \prime}$ & 9 \\
\hline Carr. Paraiso-Progreso & Progreso & Yucatan & $89^{\circ} 39^{\prime} 02^{\prime \prime}$ & $21^{\circ} 11^{\prime} 35^{\prime \prime}$ & 3 \\
\hline Chablekal & Merida & Yucatan & $89^{\circ} 34^{\prime} 37^{\prime \prime}$ & $21^{\circ} 05^{\prime} 46^{\prime \prime}$ & 9 \\
\hline Merida & Merida & Yucatan & $89^{\circ} 37^{\prime} 18^{\prime \prime}$ & $20^{\circ} 58^{\prime} 04^{\prime \prime}$ & 9 \\
\hline Yaxha & Melchor de Mencos & Peten & $89^{\circ} 24^{\prime} 00^{\prime \prime}$ & $17^{\circ} 04^{\prime} 10^{\prime \prime}$ & 250 \\
\hline
\end{tabular}


out further magnification for wing measurements. Twelve head characters from each individual were measured (Dujardin et al. 1998, 1999), while ten reference points were selected for wing measurements as indicated in Fig. 2. Measurements were taken in duplicate for both wings, while those for heads were duplicated for only $10 \%$ of samples in order to estimate exactness and precision. A closely-related species, T. phyllosoma, collected from the state of Oaxaca, was used as a species-level out-group (46 specimens).
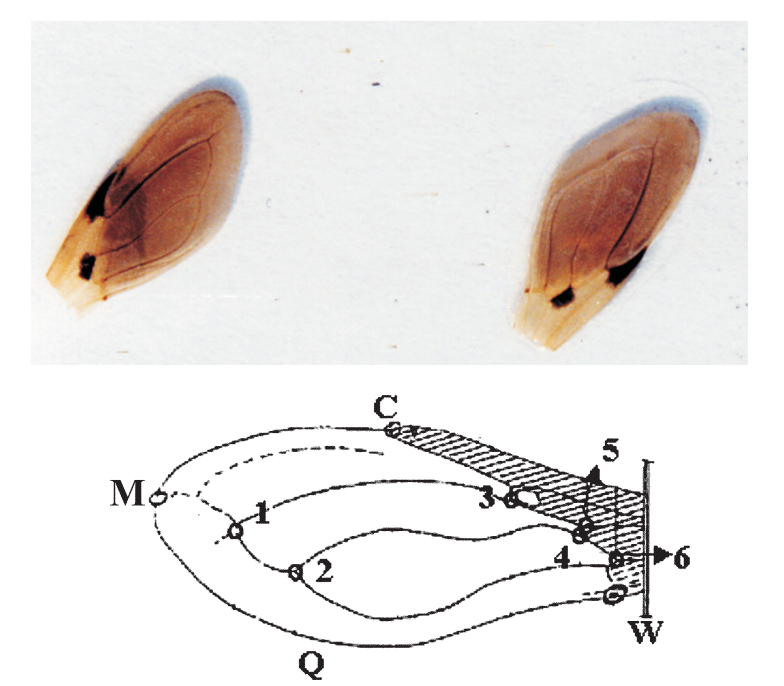

Fig. 2: diagram of wing measurements used for morphometry; measurements were taken for the distance between the following points: AA: between 1 and 3; AB: between 2 and 3; AC: between 2 and 4; $\mathrm{AD}$ : between 2 and 6; AE: between 1 and 2; AF: between 3 and 5; AG: between 4 and 6; AH: between 3 and 6; AI: between $\mathrm{C}$ and Q; AJ: between $\mathrm{C}$ and $\mathrm{W}$; $\mathrm{AK}$ : between $\mathrm{M}$ and $\mathrm{W}$.

Statistical analysis - The populations were compared using traditional morphometric methods (Rohlf \& Marcus 1993). Univariate and multivariate analyses were performed on the head and wing measurements of each specimen. The same investigator conducted the entire procedure. All measurements were compared between populations by Guillaumin graphics and using one-way analysis of variance (ANOVA) including a Bonferroni correction. The exactness and precision of measurements for each character was also calculated. The program SPSS ${ }^{\circledR}$ (version 8.0 for Windows) was used for univariate analysis. The selection criteria for variables included in the multivariate analysis was based on precision, exactness, non-redundancy, and Guillaumin profiles from log-transformed data (Dujardin 1999). Multigroup principal components were computed from the variance-covariance matrix of log-transformed selected measures to illustrate size differences among populations (data not shown). The size effects were corrected according to Klingenberg (1996) based on the multigroup model of linear growth. Discriminant analyses excluding size were conducted and are graphically represented using the first two canonical discriminant factors as axes. Cluster polygons for individuals of each group are graphed. BACwin ${ }^{\circledR}$ and PADwin ${ }^{\circledR}$ (http:// life.bio.sunysb.edu/morph) were used for multivariate analysis.

Sexual dimorphism was analyzed using a MannWhitney test between females and males from each of the four groups. A comparison of means for each character, between population groups and a t test for independence with a $95 \%$ confidence interval between males and females was analyzed for each population separately. Dimorphism based on total body length was calculated using a t test for independence for samples collected from the Yucatan, Veracruz, and San Luis Potosi. Guatemalan populations were not included in this analysis because data for complete body length was not available.

Wing asymmetry was analyzed using an ANOVA (Dujardin 1999) for each character separating groups and sexes. Both wings of each specimen were measured and measurement error estimated using all individual measurements for each character. The distribution of the averages of the differences in measurements was analyzed using Shapiro Wilk's test to determine non-directional asymmetry (fluctuating asymmetry or antisymmetry).

\section{RESULTS}

Univariate and multivariate analysis - Univariate comparisons of the head and wing measurements showed differences according to geographic location, specimens from the Yucatan were the smallest in body size, and in all measurements with the exception of characters R1, AT, and AG. Peten specimens were larger than the former, but smaller than those from Veracruz or San Luis Potosi. Peten populations clustered between San Luis Potosi-Veracruz groups and the Yucatan populations for head characters, although for wing characters, the Peten population was mixed with Veracruz and San Luis Potosi populations. Previous size and wing or head comparisons were similar independent of whether male or female populations were analyzed separately or together. Based on precision and exactness, wing and head characters selected for multivariate analysis were: $\mathrm{OE}, \mathrm{EO}, \mathrm{DE}, \mathrm{R} 1, \mathrm{R} 2, \mathrm{AA}, \mathrm{AB}, \mathrm{AE}$, AF, AI, AJ, and AK (Fig. 1).

Discriminant analysis excluding size - The $T$. phyllosoma outgroup separated completely from the four T. dimidiata populations along discriminant factor 1 (CF1) in size-free discriminant analysis (DA). Along discriminant factor 2 (CF2), Yucatan and Peten populations clearly separated from the Veracruz and San Luis Potosi populations. Discriminant analysis of wing and head characters excluding the out-group demonstrated that the CF1 separates Veracruz and San Luis Potosí populations from Yucatan and Guatemala populations, and that there is a tendency for these latter two populations to separate along CF 2 (Fig. 3). This separation was principally due to head, rather than wing characters (Fig. 4).

Females were larger than males for the majority of characters in all population groups.

All $T$. dimidiata populations had fluctuating wing asymmetry, both in male and in female populations. In general, fluctuating asymmetry was greater in males as compared to females. When comparing among the four 


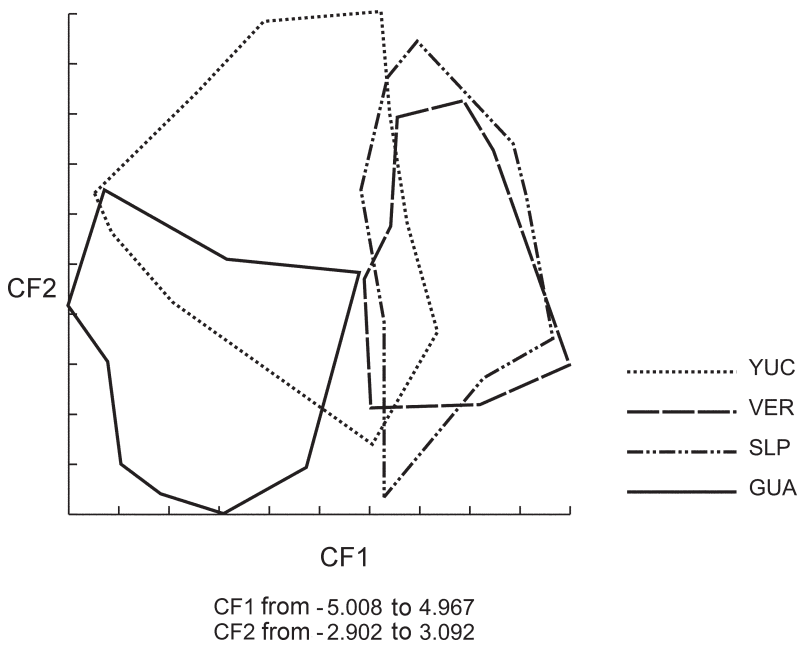

Fig. 3: discriminant analyses, showing canonical factors (CF1 and $\mathrm{CF} 2$ ), of combined head and wing measurements from female and male specimens of San Luis Potosi (SLP), Veracruz (VER), Yucatan (YUC), and Peten (GUA) populations of Triatoma dimidiata.

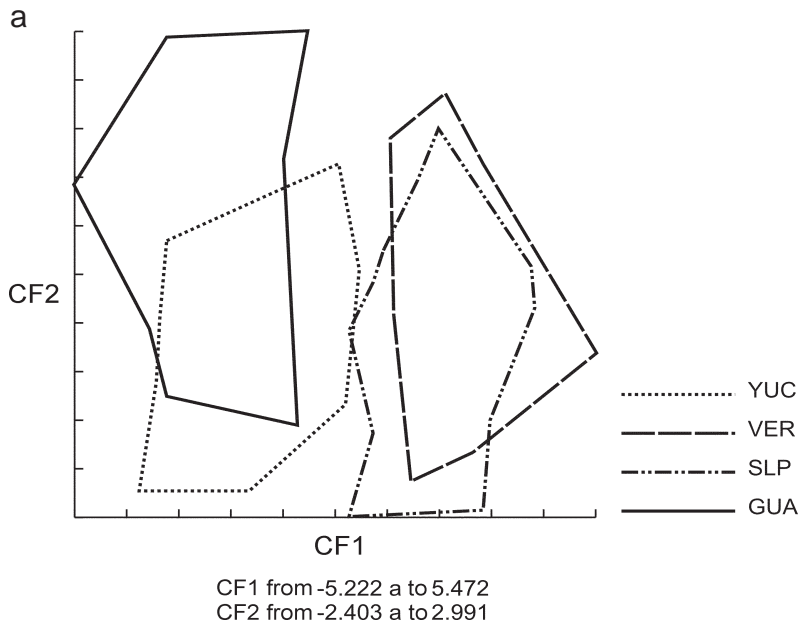

populations, males from San Luis Potosi had the highest fluctuating asymmetry, while Peten and Veracruz populations had the lowest (Fig. 5).

\section{DISCUSSION}

T. dimidiata populations have now been analyzed using ITS-2, LSU, ND4, and cyt b genetic markers (Marcilla et al. 2001, Harris et al. pers. commun.), and morphometric analysis (Bustamante et al. 2004). Although minor genetic differences were reported among most geographic isolates reported in the latter morphometric study, the primary divergent genotype of $T$. dimidiata from the Yucatan peninsula, was not analyzed. This population may represent the oldest genotype, with a 14 nucleotide difference from all other populations in Central and South America, in the ITS-2 rDNA sequence. The present study attempts to fill a gap in the analysis of this species, with the morphometric comparison of Yucatan populations with other Mexican (San Luis Potosi and Veracruz) and one other Guatemalan population from the tropical forest area of the Peten, a region close in geographic distance, but sepa-

b

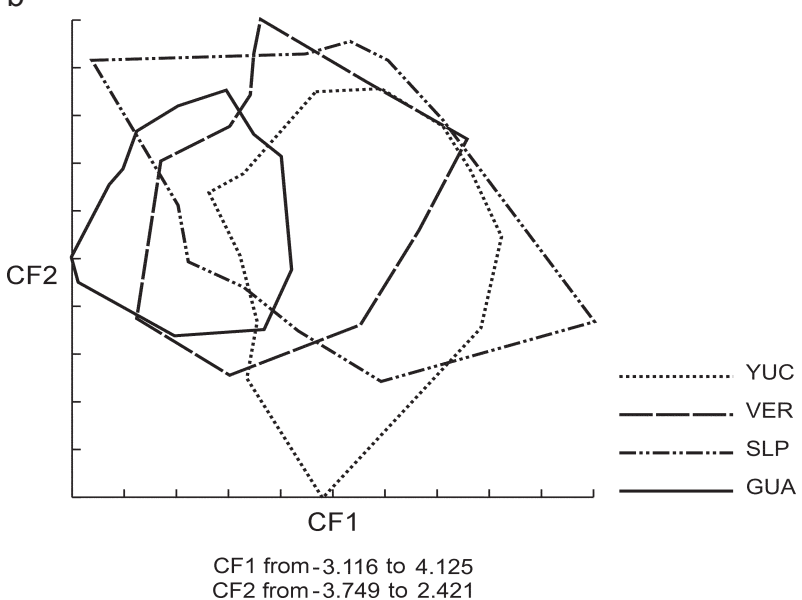

Fig. 4: discriminant analysis of head (a) and wing (b) measurements from male and female specimens of San Luis Potosi (SLP), Veracruz (VER), Yucatan (YUC), and Peten (GUA) populations of Triatoma dimidiata.

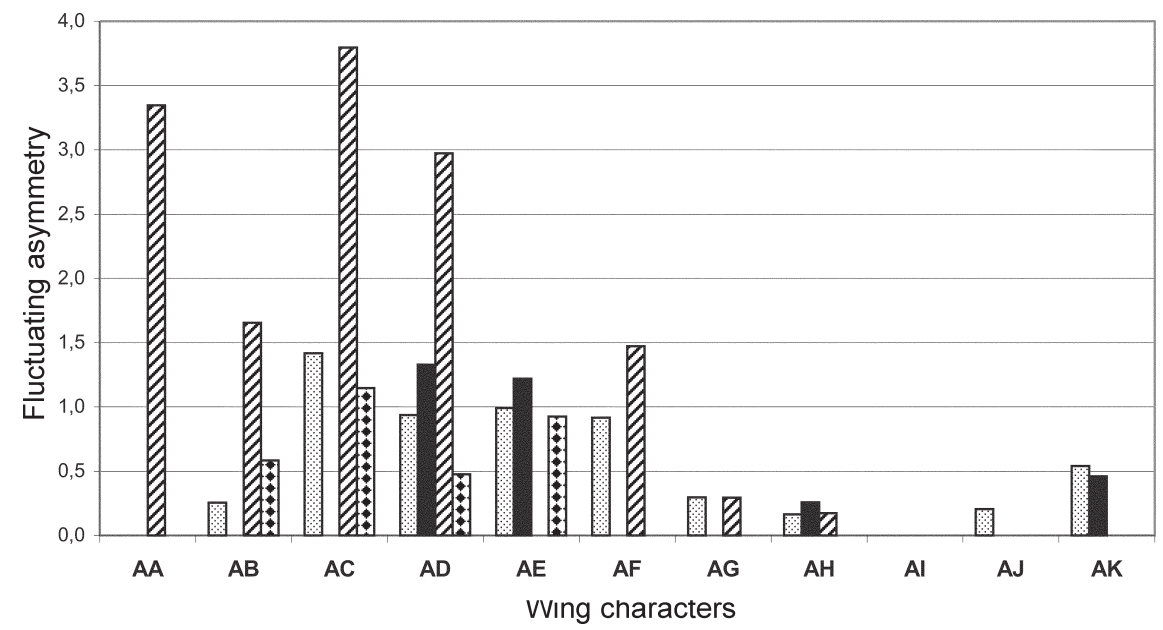

Fig. 5: indices for fluctuating wing asymmetry for male specimens of Triatoma dimidiata from San Luis Potosi (SLP), Veracruz (VER), Yucatan (YUC), and Peten (GUA). Fluctuating asymmetry was calculated using the following formula: ms-me/2 (ms: means squares, me: measurement error). 
rated by an important geographic barrier (marsh areas prone to inundation) from the Yucatan peninsula.

The Yucatan population was the smallest in size of the four populations studied herein, despite originating from peridomestic habitat (Peten samples were the only sylvan specimens analyzed). The smaller size of specimens has been associated previously with population adaptation to domestic habitats, in both Rhodnius prolixus (Harry 1994) and T. infestans (Dujardin et al. 1997). In T. pallidipennis, another North American and close taxonomic species to $T$. dimidiata, populations from sylvan habitats also are larger than populations collected in domestic areas (Ordoñez, unpublished observations). Further analysis of both sylvan and domestic specimens from within each population of $T$. dimidiata will be required to identify any habitat-associated differences in size, although in all populations studied herein, the females were larger than the males, as has been reported for other triatomine species.

Yucatan and Peten populations overlapped albeit with certain differentiation in shape, using discriminant analysis; both were clearly separated from Veracruz and San Luis Potosi populations, which were virtually identical. However, in a previous morphometric study (Bustamante et al. 2004), there was some overlap between the sylvan Peten population and the domestic Tuxpan (Veracruz) populations in the allometry free analysis. This apparent discrepancy with the present data can be explained by the recent finding that more than one ITS-2 genotype has been identified in the Peten region, one similar to the Yucatan population and another similar to the Veracruz genotype (Bargues, unpublished observations). This may explain the morphometric similarity between Yucatan and Peten populations observed herein, despite previous report of important ITS-2 sequence divergence in populations from the two areas (Marcilla et al. 2001). T. dimidiata from the Yucatan and Peten populations not only share morphometric traits, but also some biological and behavioral characteristics, such as the "seasonal human migration" described by Dumonteil et al. (2002) and Bustamante et al. (2004).

Despite the use of both wing and head characters in this study, only those from heads were informative for population level differences. Casini et al. (1995) analyzed specimens of T. infestans from Uruguay and also found that wing measurements did not influence discriminant analysis, while head characters were necessary to distinguish between sylvan and domestic populations.

Although wing characters were not important for population level differentiation, specimens from all populations had fluctuating wing asymmetry. Specimens, particularly males, from San Luis Potosi, had the highest fluctuating asymmetry indices, indicating lower genetic variability in domestic populations from the species' northern distribution limit. Given the similarity between San Luis Potosi and Veracruz populations, it is interesting that fluctuating wing asymmetry was quite distinct between the two populations, indicating a far more domestic population from the former. It is interesting to note that Dujardin et al.
(1997) found major fluctuating asymmetry in females, but not in males of $T$. infestans.

T. dimidiata from Mexico is indeed polymorphic, with apparent population isolation despite important geographic barriers. The Yucatan genotype and morphotype have not been isolated from any other region in Mexico, although its presence in the Peten, an extension of the peninsula, is not surprising. What is surprising, however, is the presence in the Peten of two different morphoand genotypes in sylvan areas. We do not see a mixing of morphotypes in the west region of the Peten in Tabasco, rather a distinct separation of Yucatan morphotypes east of the Grijalva river delta, and Veracruz morphotypes west of the same river. Further studies will be required to determine whether hybrid morpho- and genotypes exist in this "transition" area, and if not, what genetic mechanisms play a role in maintaining isolation of the morphotypes, despite man-assisted and triatomine adult flight dispersion potential.

\section{REFERENCES}

Bustamante DM, Monroy C, Menes M, Rodas A, SalazarSchettino PM, Rojas G, Pinto N, Guhl F, Dujardin JP 2004. Metric variation among geographic populations of the Chagas vector Triatoma dimidiata (Hemiptera:Reduviidae: Triatominae) and related species. J Med Entomol 41: 296301.

Casini CE, Dujardin JP, Martinez M, Bentos-Pereira A, Salvatella R 1995. Morphometric differentiation between two geographic populations of Triatoma infestans in Uruguay. Res Rev Parasitol 55: 25-30.

Dujardin JP 1999. Memorias, Curso Morfometría Geométrica, Morfometría Tradicional y Biología Evolutiva, La Rioja, Argentina, Sep 27-Oct 7.

Dujardin JP, Bermudez H, Casini C, Schofield CJ, Tibayrenc M 1997. Metric differences between sylvatic and domestic Triatoma infestans (Heteroptera:Reduviidae) in Bolivia. $J$ Med Entomol 34: 544-551.

Dujardin JP, Morgues G, Torrez M, Martínez E, Cordoba C, Gianella A 1998. Morphometrics of domestic Panstrongylus rufotuberculatus in Bolivia. Ann Trop Med Parasitol 92: 219-228.

Dujardin JP, Steindel M, Chavez T, Machane M, Schofield CJ 1999. Changes in the sexual dimorphism of Triatominae in the transition from natural to artificial habitats. Mem Inst Oswaldo Cruz 94: 565-569.

Dumonteil E, Gourbiere S, Barrera-Perez M, Rodriguez-Felix E, Ruiz-Pina H, Banos-Lopez O, Ramirez-Sierra MJ, Menu F, Rabinovich JE 2002. Geographic distribution of Triatoma dimidiata and transmission dynamics of Trypanosoma cruzi in the Yucatan Peninsula of Mexico. Am J Trop Med Hyg 67: 176-183.

Harry M 1994. Morphometric variability in the Chagas disease vector Rhodnius prolixus. Jpn J Genet 69: 233-250.

Klingenberg CP 1996. Multivariate allometry. In LF Marcus, M Conti, A Loy, GJ Naylor, D Slice (eds), Advances in Morphometrics. Proceedings of the NATO-ASI on Morphometrics, Plenum Pres, New York, p. 23-49.

Lent H, Wygodzinsky P 1979. Revision of the Triatominae 
(Hemiptera:Reduviidae), and their significance as vectors of Chagas disease. Bull Am Mus Nat His 163: 127-520.

Marcilla A, Bargues MD, Ramsey J, Magallon E, Salazar PM, Abad-Franch F, Dujardin JP, Schofield CJ, Mas-Coma S 2001. The ITS-2 of the nuclear rDNA as a molecular marker for populations, species and phylogenetic relationships in Triatominae (Hemiptera:Reduviidae), vectors of Chagas disease. Mol Phylogenet Evol 18: 136-142.

Ramsey JM, Ordóñez R, Tello López A, Pohls JL Sánchez V, Peterson AT 2003. Actualidades sobre la epidemiología de la enfermedad de Chagas en México. In JM Ramsey, A Tello López, JL Pohls (eds). Iniciativa para la Vigilancia y el
Control de la Enfermedad de Chagas en la República Mexicana, Instituto Nacional de Salud Pública, Cuernavaca Morelos, p. 85-103.

Rohlf FJ, Marcus L 1993. A revolution in morphometrics. Trends Ecol Evol 8: 129-132.

Vidal-Acosta V, Ibáñez-Bernal S, Martínez-Campos C 2000. Infección natural de chinches Triatominae con Trypanosoma cruzi asociadas a la vivienda humana en México. Sal Pub Mex 42: 496-503.

Zarate LG, Zarate RJ 1985. A checklist of the Triatominae (Hemiptera:Reduviidae) of Mexico. Int J Entomol 27: 102127. 